\title{
'Trying to put a square peg into a round hole': a qualitative study of healthcare professionals' views of integrating complementary medicine into primary care for musculoskeletal and mental health comorbidity
}

\author{
Deborah Sharp ${ }^{1}$, Ava Lorenc ${ }^{1 *}$, Gene Feder ${ }^{1}$, Paul Little ${ }^{2}$, Sandra Hollinghurst ${ }^{1}$, Stewart Mercer ${ }^{3}$ \\ and Hugh MacPherson ${ }^{4}$
}

\begin{abstract}
Background: Comorbidity of musculoskeletal (MSK) and mental health (MH) problems is common but challenging to treat using conventional approaches. Integration of conventional with complementary approaches (CAM) might help address this challenge. Integration can aim to transform biomedicine into a new health paradigm or to selectively incorporate CAM in addition to conventional care. This study explored professionals' experiences and views of CAM for comorbid patients and the potential for integration into UK primary care.

Methods: We ran focus groups with GPs and CAM practitioners at three sites across England and focus groups and interviews with healthcare commissioners. Topics included experience of co-morbid MSK-MH and CAM/integration, evidence, knowledge and barriers to integration. Sampling was purposive. A framework analysis used frequency, specificity, intensity of data, and disconfirming evidence.
\end{abstract}

Results: We recruited 36 CAM practitioners (4 focus groups), 20 GPs (3 focus groups) and 8 commissioners (1 focus group, 5 interviews).

GPs described challenges treating MSK-MH comorbidity and agreed CAM might have a role. Exercise- or self-care-based CAMs were most acceptable to GPS. CAM practitioners were generally pro-integration.

A prominent theme was different understandings of health between CAM and general practitioners, which was likely to impede integration. Another concern was that integration might fundamentally change the care provided by both professional groups. For CAM practitioners, NHS structural barriers were a major issue. For GPs, their lack of CAM knowledge and the pressures on general practice were barriers to integration, and some felt integrating CAM was beyond their capabilities. Facilitators of integration were evidence of effectiveness and cost effectiveness (particularly for CAM practitioners). Governance was the least important barrier for all groups.

There was little consensus on the ideal integration model, particularly in terms of financing. Commissioners suggested CAM could be part of social prescribing.

(Continued on next page)

\footnotetext{
* Correspondence: ava.lorenc@bristol.ac.uk

${ }^{1}$ Centre for Academic Primary Care, School of Social and Community

Medicine, University of Bristol, Canynge Hall, 39 Whatley Road, Bristol BS8

2PS, UK

Full list of author information is available at the end of the article
}

(c) The Author(s). 2018 Open Access This article is distributed under the terms of the Creative Commons Attribution 4.0 International License (http://creativecommons.org/licenses/by/4.0/), which permits unrestricted use, distribution, and reproduction in any medium, provided you give appropriate credit to the original author(s) and the source, provide a link to the Creative Commons license, and indicate if changes were made. The Creative Commons Public Domain Dedication waiver (http://creativecommons.org/publicdomain/zero/1.0/) applies to the data made available in this article, unless otherwise stated. 
(Continued from previous page)

Conclusions: CAM has the potential to help the NHS in treating the burden of MSK-MH comorbidity. Given the challenges of integration, selective incorporation using traditional referral from primary care to CAM may be the most feasible model. However, cost implications would need to be addressed, possibly through models such as social prescribing or an extension of integrated personal commissioning.

Keywords: Primary care, Complementary medicine, Integrated medicine, Qualitative, NHS, Musculoskeletal, Mental health, Comorbidity

\section{Background}

Mental health (MH) and musculoskeletal (MSK) conditions create a huge burden for patients, society and healthcare services. Globally, low back pain is the leading cause of disability [1], and in the UK MSKs account for $30 \%$ of GP consultations [2] and 30.8 million working days lost annually [3]. Mental ill health is the single largest cause of disability in the UK [4], uses more than $11 \%$ of the NHS (National Health Service) budget [5] and costs the UK economy $£ 70-£ 100$ billion/year [4]. Comorbidity of MH and MSK conditions is common $\mathrm{MH}$ problems (anxiety or depression) are 4 times more common in those with persistent pain than in those without [6, 7] and MSK and MH conditions co-occur in $3 \%$ of working age (16-64 years) people in England [8]. People with low back pain are significantly more likely to have depression, anxiety and sleep disorders, and to be prescribed medication for these conditions, than those without [9]. Comorbidity is particularly concerning to GPs [10] and poorly addressed by current guidelines, evidence and practice [11], representing an 'effectiveness gap' (where available treatments are sub-optimally effective), which complementary and alternative medicine (CAM) may be able to fill [11-13]. CAM is commonly used by those with comorbid $\mathrm{MH}$ and MSK conditions [14, 15].

Although most commonly accessed privately in the UK, CAM can be integrated with conventional (NHS) care. Wiese and colleagues [16] describe three models of integration: 1) pluralism, a patient-based model, where the patient chooses which approach to use, in a 'supermarket' approach [17]; 2) selective incorporation, or integrated medicine, the co-optation of CAM by biomedicine, with CAM as an add-on, provided by trained conventional practitioners or CAM practitioners (on-site or off-site and funded by the NHS/patient/charity; and 3) integrative medicine or transformative integration, which aims to merge biomedicine into a new health paradigm incorporating a holistic approach and providing optimum treatment from any tradition [17-19]. This paper focusses on the second model. Compared to the consumerist approach of the first model, integrated and integrative medicine can promote continuity of care, address safety concerns, and reduce professional power struggles [20]. The third model, transformative integration, may still be a utopian ideal [19], whereas selective incorporation is preferred by biomedical staff [16]. In primary care, selectively incorporated CAM is more commonly delivered by CAM practitioners than conventional practitioners [21, 22]. Selective incorporation, where patients are referred from conventional healthcare to an off-site CAM practitioner, is similar to social prescribing, a system enabling primary care clinicians to refer patients to a broad range of community services, for example an exercise class or gardening club [23].

Many of the defining values of CAM are now considered part of mainstream care. These include patientcentred care and a holistic approach [24, 25], and emphasis on self-management and prevention, which are prominent goals in current UK health service policy planning [26, 27]. Person- and community-centred approaches to health and wellbeing have a key role in these plans, which can include CAM [28]. Primary care may be the area of the NHS where CAM would fit most comfortably, due to both primary care and CAM having a holistic outlook, emphasis on self-care and strong therapeutic relationships.

Primary healthcare professionals, including GPs, tend to be most positive about CAM for chronic self-limiting conditions or those with limited treatment options e.g. musculoskeletal [29] or chronic pain [29-31]. Other 'effectiveness gaps' include depression, anxiety and stress [13].There is very little research on CAM for comorbid MSK-MH. The sparse qualitative research with GPs and CAM practitioners about integration of CAM into publicly funded health care is rarely health condition-specific, and rarely addresses commissioning issues. Doctors' views on CAM in general vary widely, from enthusiastic to sceptical, with sceptical or uncertain the dominant view [32], although one survey found that only $6 \%$ of primary care professionals were against integration of CAM [29]. Attitudes vary depending on the specific CAM approach - a survey of general practitioners (GPs) found that nearly $60 \%$ support acupuncture provision on the NHS [33]. Healthcare practitioners' views on CAM are mainly based on professional rather than personal factors [34], in particular the limited evidence base [30,32], although referral is often determined by patient preference $[29,35]$. 
However, there are challenges to transformative integration and selective incorporation. Based on previous studies of generic integrative services, mainly from the point of view of conventional and CAM clinicians, these can include: preserving the epistemological stance of $\mathrm{CAM}$, as conventional medicine tends to dominate [12, 19, 20]; differing 'corporate cultures' [36, 37]; professional conflicts; conventional practitioners' lack of knowledge regarding CAM [38]; a lack of communication and collaboration between the two groups [37]; a limited evidence base for many CAM; and lack of time in NHS settings [31, 39]. Integration can also give rise to issues around regulation of quality and safety, and duty of care. This particularly applies to a referral model, given UK General Medical Council advice that GPs delegating care must be satisfied with the safety and quality of care, and the practitioner's knowledge, skills and experience [40].

Integrated medicine may help to address comorbid MSK and MH conditions, but there is a lack of research specific to this clinical area. This study therefore sought to explore healthcare professionals' views and experiences to identify the feasibility of integrating CAM for comorbid $\mathrm{MH}$ and MSK into UK National Health Service (NHS) primary care.

\section{Methods}

We have followed COREQ guidelines in reporting this study [41].

This study explored the views and experiences of GPs, CAM practitioners and healthcare commissioners. This included their views of CAM and any experiences of CAM provision in an integrated fashion in NHS primary care settings; and their views on the potential for and challenges of integrating CAM into primary care, particularly for comorbid MSK and MH conditions.

For GPs and CAM practitioners, focus groups were conducted at three sites across England (A, B, C). A is a fairly large city in the south of England. $\mathrm{B}$ and $\mathrm{C}$ are moderately sized cities, B in the North and C in the South of England. For commissioners, a combination of focus groups and telephone interviews were conducted, as participants were located throughout England.

CAM practitioners were recruited through a variety of routes including the Complementary and Natural Healthcare Council (CNHC) mailing list and Facebook group, professional organisation online registers $(\mathrm{CNHC}$, British Acupuncture Council, General Osteopathic Council, British Chiropractic Association, UK Tai chi union), Google searches, NHS hospital pain clinics using CAM, and NHS physiotherapy services. GPs were recruited by local CLRNs (Clinical Local Research Networks). Commissioners were recruited via an NHS management fellow at Bristol University, the project steering group, and commissioners of integrated medicine services in the UK. All potential participants were contacted by email, with telephone follow-up.

Sampling was purposive. For CAM practitioners, the criteria were type of CAM and NHS experience/training. For GPs they were practice location (urban/rural), practice socioeconomic characteristics, gender, ethnic background, attitudes to and experiences of CAM (as self-reported by potential participants in an email). We aimed to include commissioners with experience of commissioning CAM, particularly for MSK and MH, as well as in a variety of geographical locations. We did not collect data on reasons for non-response.

GP/CAM focus groups lasted $90 \mathrm{~min}$ and were held on university premises. Two researchers attended each focus group, one (AL) to lead the group and ask the questions, the other noting who spoke and non-verbal communication. AL is a senior research associate with experience of conducting interviews and focus groups, including a $\mathrm{PhD}$ using qualitative methods. Participants were offered payment for their time, for themselves or their employer. They were aware that the researcher was pro-CAM. The researcher aimed to maintain an objective stance regarding CAM during the interviews. Participants were assigned codes to ensure confidentiality. Topic guides were developed for the study (see Additional file 1). For CAM practitioners, questions focussed on experience in the NHS, experience treating patients with MSK and MH comorbidity, the evidence base for their therapy, relationships with GPs and barriers to integrating CAM into NHS primary care. GPs were asked about their experience of treating patients with comorbid MSK and MH, their knowledge and experience of CAM (in particular, referring their patients to CAM practitioners), and barriers to integrating CAM into NHS primary care.

Commissioners' focus groups and interviews lasted between 15 and $60 \mathrm{~min}$ and were conducted by one researcher (AL). Interviews were either face-to-face, via telephone or video link. The choice between interview or focus group was based on participant preference and availability. Commissioners were offered payment for their time. The topic guide was developed for the study (see Additional file 1) and included questions about definitions and beliefs regarding CAM, experience of commissioning CAM, factors in commissioning decisions, experience of MSK and MH services, barriers to integration of CAM, and thoughts about what evidence might persuade them to commission a CAM service.

Digital audio recordings were transcribed verbatim by a professional company, with non-verbal communication added from our notes. Based on content analysis, a framework was used for all data analysis [42, 43]. Framework analysis is highly structured and systematic, providing a 
clear map of how analysis and interpretation were performed [42]. It facilitates constant reference back to the original data, to remain grounded [42], but is also structured around pre-set aims and objectives, allowing the answering of specific research questions in the participants' language, in concordance with the abductive stance taken [44]. It consists of five key stages: familiarisation, identifying a framework, indexing, charting and mapping/interpreting [43]. The first four are mainly data management strategies, to order, sort, synthesise and condense the raw data, the bulk of interpretation takes place in the final mapping stage [43]. Data analysis was facilitated using Microsoft Excel and NVivo (computer assisted qualitative data analysis software developed to facilitate systematic and clear analysis) [45]. Familiarisation came through reading the transcripts. A framework of codes was developed from the data, with some a priori themes from the topic guides. Indexing involved comprehensively labelling all the data using the final framework, marking quotations (sentences, paragraphs) which belonged to a code. Charting was performed using the Framework function in NVivo, which uses a matrix, where each row was a participant and each column a code. A summary of the data was entered into each cell in the framework, using quotations as much as possible, with some synthesis and abstraction to make meaning clear [46] but using participant's words and terms, to stay grounded in the data [42]. The final stage of mapping and interpreting was done in Microsoft Excel. Each column was interrogated for themes. At all stages the 'strength' of data was considered, which was based on the following criteria:

- Frequency (number of people) and extensiveness (length) of comments, not as absolute data but to provide an indication of importance [42].

- Specificity: quotes relating to a personal experience were considered more important than hypothetical references [47].

- Intensity or depth of feeling, for example, are the words positive, negative, middling [48]. Internal consistency (changes in individual's views) was also considered [48].

- Disconfirming evidence [49] and negative/deviant cases [50] either proposed alternative explanations, reinforced normative theories by providing unusual examples, explained individual variation from the norm, or refined theories

The study was approved by the University of Bristol Faculty of Medicine and Dentistry Research Ethics Committee (FREC) on 3rd July 2015, reference 21,603. Assurance was provided by the relevant NHS organisations for each of the sites.

\section{Results}

Of the 55 CAM practitioners invited, 36 took part in 4 focus groups (65\% response rate), two in Site A, one in Site B and one in Site C. Table 1 provides their details. Five practiced tai chi, four acupuncture, and three practiced each of yoga, mindfulness, hypnotherapy, osteopathy, massage. Two practiced nutritional therapy and two chiropractic, one practised homeopathy and one herbal medicine. Participants worked in a variety of settings: most were private but fourteen were located in the NHS, including GP practices, psychological therapy and pain clinics. Seven were NHS professionals (GP, consultant, nurse, occupational therapist, physiotherapist). Eleven were statutorily regulated (NHS professionals, osteopaths or chiropractors) and 21 voluntarily regulated (voluntarily registered with a regulatory body).

Fifty-five GPs expressed an interest in participating, seven of whom subsequently declined and 28 could not attend due to timing. The final sample was predominantly based on GPs' availability, although purposive sampling criteria were met. Twenty GPs (see Table 2) participated, in three focus groups, ten in Site A, six in Site B and four in Site C. Most stated their views as neutral or in favour of CAM, three were 'sceptical'. Four practised CAM.

Of 30 commissioners invited, eight took part, most of whom were also GPs (Table 3). Six worked in CCGs (clinical commissioning group - NHS bodies responsible for commissioning local services), one in an integrated personal commissioning (a scheme using personal health budgets for patients/carers) demonstration site and one for the voluntary sector. One focus group was conducted with three participants; the others' views were obtained through telephone interviews.

The key themes arising from the data were: what is CAM; the role of CAM; feasibility of integrated medicine in the NHS; barriers to integration; GP education; regulation; and models of integration.

\section{What is CAM?}

CAM was a difficult term for many GPs as it covers a wide range of interventions. Three GPs mentioned the 'huge' range of CAM and grouping this diverse range of treatments as 'CAM', was seen as 'unhelpful'.

"I really, really struggle with this umbrella term of complementary and alternative medicine, because I see a huge spectrum" (GP A9)

Two described a spectrum of CAM based on effectiveness and safety, with chiropractic and osteopathy at one end and "mumbo jumbo", e.g. homeopathy and reiki at the other. Some therapies - Pilates, yoga, tai chi, mindfulness and acupuncture - were not necessarily 
Table 1 Participants in CAM practitioner focus groups

\begin{tabular}{|c|c|c|c|c|c|c|c|}
\hline Code $^{a}$ & CAM & Clinical setting & $\begin{array}{l}\text { Statutorily } \\
\text { regulated? }\end{array}$ & $\begin{array}{l}\text { Voluntarily } \\
\text { regulated? }\end{array}$ & $\begin{array}{l}\text { NHS } \\
\text { professional? }\end{array}$ & $\begin{array}{l}\text { Practices } \\
\text { in NHS? }\end{array}$ & $\begin{array}{l}\text { Is your practice } \\
\text { integrated into NHS? }\end{array}$ \\
\hline A1.1 & Mindfulness & $\begin{array}{l}\text { Improving access to } \\
\text { psychological therapies } \\
\text { (IAPT), occupational therapy, } \\
\text { pain clinic }\end{array}$ & YES & YES & YES & YES & YES \\
\hline A1.2 & Yoga & Private & NO & YES & NO & NO & NO \\
\hline A1.3 & Holistic massage, reiki & Private & NO & NO & NO & NO & NO \\
\hline A1.4 & Mindfulness & IAPT & NO & YES & NO & YES & YES \\
\hline A1.5 & Osteopathy & Private, in GP practice & YES & NO & NO & YES & NO \\
\hline A1.6 & Osteopathy & Private, in GP practice & YES & NO & NO & YES & NO \\
\hline A1.7 & $\begin{array}{l}\text { Manipulation, Bach flowers, } \\
\text { homeopathy, acupressure }\end{array}$ & General practice & YES & YES & YES & YES & YES \\
\hline A1.8 & Pilates, yoga & Private & \multicolumn{5}{|c|}{ Missing data } \\
\hline A1.9 & Massage, yoga (individual) & Private & NO & YES & NO & NO & NO \\
\hline A2.1 & Tai chi, qigong & Private; chronic patients & NO & NO & NO & NO & NO \\
\hline A2.10 & $\begin{array}{l}\text { Homeopathy, Director of } \\
\text { integrative medicine centre }\end{array}$ & $\begin{array}{l}\text { Community interest } \\
\text { company; NHS }\end{array}$ & NO & YES & YES & YES & YES \\
\hline A2.2 & $\begin{array}{l}\text { Physiotherapy, adapted tai } \\
\text { chi, Pilates }\end{array}$ & NHS rheumatology & YES & NO & YES & YES & YES \\
\hline A2.3 & Hypnotherapy & Private clinic with a physiotherapist & NO & YES & NO & NO & NO \\
\hline A2.4 & Massage, reiki & $\begin{array}{l}\text { Private osteopathy clinic } \\
\text { attached to a GP surgery }\end{array}$ & NO & YES & NO & YES & Yes \\
\hline A2.5 & Acupuncture & Low cost clinic & NO & YES & NO & NO & NO \\
\hline A2.6 & Acupuncture, meditation & $\begin{array}{l}\text { Cancer centre, multi-bed } \\
\text { clinic, community interest } \\
\text { company }\end{array}$ & NO & YES & NO & NO & YES \\
\hline A2.7 & Tai chi & Private & NO & NO & NO & NO & NO \\
\hline A2.8 & Pain management & NHS pain clinic & YES & NO & YES & YES & YES \\
\hline A2.9 & $\begin{array}{l}\text { Alexander technique, } \\
\text { medical acupuncture }\end{array}$ & Nurse, NHS pain clinic & YES & YES & YES & YES & YES \\
\hline B1 & Tai chi & $\begin{array}{l}\text { Private; collaboration with } \\
\text { NHS }\end{array}$ & YES & YES & NO & $\begin{array}{l}\text { YES } \\
\text { (PREVIOUS) }\end{array}$ & SOMETIMES \\
\hline B2 & Mindfulness & $\begin{array}{l}\text { Charitable; previously local } \\
\text { educational authority }\end{array}$ & YES & NO & NO & NO & NO \\
\hline B3 & Mindfulness & Former GP; private & NO & YES & $\begin{array}{l}\text { NO } \\
\text { (retired GP) }\end{array}$ & NO & NO \\
\hline B4 & Microsystems Acupuncture & Private; charitable & NO & YES & NO & YES & NO \\
\hline B5 & $\begin{array}{l}\text { Medical herbalist, nutritional } \\
\text { therapist }\end{array}$ & Private & NO & YES & NO & NO & NO \\
\hline B6 & Tai chi & $\begin{array}{l}\text { Primary and secondary care } \\
\text { and community mental health }\end{array}$ & NO & NO & NO & NO & YES \\
\hline B7 & Yoga therapy & Private & NO & YES & NO & NO & NO \\
\hline B8 & $\begin{array}{l}\text { Craniosacral, acupuncture, } \\
\text { Kampo herbs }\end{array}$ & Private & NO & YES & NO & NO & NO \\
\hline C1 & Chiropractic & Private & YES & NO & NO & NO & NO \\
\hline$C 2$ & Tai Chi and qigong & Private & NO & YES & NO & NO & NO \\
\hline C3 & Hypnotherapy & Private & \multicolumn{5}{|l|}{ Missing data } \\
\hline C4 & Chiropractic & Private & YES & NO & NO & NO & NO \\
\hline C5 & Yoga & Hospital; private & NO & YES & NO & NO & NO \\
\hline C6 & Physio & NHS Hospital & YES & N/A & YES & YES & YES \\
\hline
\end{tabular}


Table 1 Participants in CAM practitioner focus groups (Continued)

\begin{tabular}{|c|c|c|c|c|c|c|c|}
\hline Code $^{a}$ & CAM & Clinical setting & $\begin{array}{l}\text { Statutorily } \\
\text { regulated? }\end{array}$ & $\begin{array}{l}\text { Voluntarily } \\
\text { regulated? }\end{array}$ & $\begin{array}{l}\text { NHS } \\
\text { professional? }\end{array}$ & $\begin{array}{l}\text { Practices } \\
\text { in NHS? }\end{array}$ & $\begin{array}{l}\text { Is your practice } \\
\text { integrated into NHS? }\end{array}$ \\
\hline$C 7$ & $\begin{array}{l}\text { Acupuncture, Chinese } \\
\text { herbal medicine }\end{array}$ & Private & NO & YES & NO & NO & $\mathrm{NO}$ \\
\hline C8 & Hypnotherapy & Private; volunteer & NO & YES & NO & YES & NO \\
\hline C9 & $\begin{array}{l}\text { Osteopathy, Heart Math, } \\
\text { Alexander technique }\end{array}$ & $\begin{array}{l}\text { Homeless health care; } \\
\text { private }\end{array}$ & \multicolumn{3}{|l|}{ Missing data } & YES & Missing data \\
\hline
\end{tabular}

${ }^{a}$ As two focus groups were conducted at Site $A$ these are coded A1 and A2

considered to be complementary, and exercise-based CAM - Pilates, tai chi, yoga - seemed to be more acceptable to GPs. Some were also more positive about CAM which 'foster' self-management.

"...nothing weird or wonderful there at all [acupuncture, tai chi, yoga], those are all things that are part of our everyday...I wouldn't even particularly class any of those as complementary medicines" (GP A6)

"Self-care is so important. Teach someone to look after their sleep and not be so concerned about it, or to increase their core stability by using something for themselves, is much better than perhaps referring them to the homoeopathist and

Table 2 Participants in GP focus groups

\begin{tabular}{|c|c|c|c|c|c|}
\hline Code & Attitude to $\mathrm{CAM}^{a}$ & CAM practitioner? & $\begin{array}{l}\text { Deprivation in practice } \\
\text { area (as reported by the GP) }\end{array}$ & Ethnicity & $\begin{array}{l}\text { Practice } \\
\text { location }\end{array}$ \\
\hline A1 & Neutral & No & Average & White & Semi-rural \\
\hline$A 2$ & In favour & No & Deprived & $\begin{array}{l}\text { Mixed race (Asian/ } \\
\text { Caucasian) }\end{array}$ & Urban \\
\hline A3 & Neutral but open & $\begin{array}{l}\text { Yes, anthroposophic } \\
\text { medicine }\end{array}$ & Mixed & Non-White & Urban \\
\hline A4 & In favour & $\begin{array}{l}\text { Yes, acupuncture (British Medical } \\
\text { Acupuncture Society, BMAS) }\end{array}$ & Deprived & White & Urban \\
\hline A5 & In favour & $\begin{array}{l}\text { Previously (acupuncture, } \\
\text { homeopathy) }\end{array}$ & Average & White & $\begin{array}{l}\text { Semi-rural/ } \\
\text { suburban }\end{array}$ \\
\hline A6 & $\begin{array}{l}\text { Opposed to NHS funded } \\
\text { CAM }\end{array}$ & No & Fairly deprived & White & Urban \\
\hline A7 & Mixed (depends on therapy) & Yes, acupuncture (BMAS) & Not deprived & White & Urban \\
\hline A8 & In favour & No & Not deprived & White & Semi urban \\
\hline A9 & $\begin{array}{l}\text { Mixed (depends on therapy, } \\
\text { payment etc) }\end{array}$ & No & Some deprivation & White & Urban \\
\hline A10 & In favour & No & Students & White & Urban \\
\hline B1 & $\begin{array}{l}\text { Previously sceptical, becoming } \\
\text { more open }\end{array}$ & $\begin{array}{l}\text { No (acupuncture provided } \\
\text { at surgery) }\end{array}$ & Deprived & White & Rural \\
\hline B2 & Neutral & No & Data missing & White & Locum \\
\hline B3 & Sceptical & No & Locum & White & Variety \\
\hline B4 & $\begin{array}{l}\text { Open-minded but depends } \\
\text { on the evidence }\end{array}$ & $\begin{array}{l}\text { No (acupuncture provided } \\
\text { at surgery) }\end{array}$ & Lower deprivation & Non-White & Suburban \\
\hline B5 & Data missing & No & Mixed & White & Data missing \\
\hline B6 & Data missing & Yes, acupuncture & Data missing & Data missing & Data missing \\
\hline C1 & Neutral & No & Affluent & White & Rural/urban \\
\hline C2 & In favour (if evidence-based) & No & Pockets of deprivation & White & Semi-rural \\
\hline C4 & Sceptical/neutral & No & Deprived & White & Urban \\
\hline C5 & $\begin{array}{l}\text { Sceptical (but open to } \\
\text { persuasion) }\end{array}$ & No & Mixed & White & Urban \\
\hline
\end{tabular}

aThis is the respondent's response to asking in an email "We are hoping that the focus groups comprise people with a diversity of opinion - would you say in general you are in favour of CAM, opposed to CAM or simply neutral?" 
Table 3 Participants in commissioner focus groups/interviews

\begin{tabular}{lllll}
\hline Code & Commissioning body/employer & Clinician? & Location in UK & Focus group or interview \\
\hline 1 & CCG $^{\text {a }}$ & Former GP & South West & Focus group \\
2 & CCG & GP & London & Telephone interview \\
3 & CCG (pharmacy services) & GP & South West & Focus group \\
4 & Integrated personal commissioning & No & South West & Telephone interview \\
5 & CCG & GP & North & Telephone interview \\
6 & CCG & GP & London & Focus group \\
7 & CCG (self-care lead) & GP & South West & Telephone interview \\
8 & Voluntary sector - social prescribing & No & North & Telephone interview \\
\hline
\end{tabular}

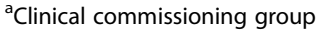

they lay out their store of symptoms again" (GP

B5)

The most common criteria used to define CAM were its 'philosophical approach' and its lack of an evidence base. Six GPs talked about CAM as being treatments with a philosophy they perhaps did not accept or understand. For four GPs, the lack of evidence defined CAM, although another felt this did not distinguish it from conventional care. For commissioners, CAM was defined as treatment outside the mainstream.

"I suppose it's [CAM] almost defined by what is in conventional, it's the other things that are not considered conventional" (commissioner 7)

"I would say that anything that doesn't have a solid evidence base would come under the principles of complementary medicine" (GP A6)

GPs discussed two particular areas of overlap between CAM and conventional medicine: exercise (e.g. tai chi) and social support (e.g. personal health budgets). For commissioners, CAM overlapped considerably with broader approaches such as social prescribing and holistic care.

\section{A role for CAM in primary care and MSK-MH comorbidity}

All three groups felt that CAM had a role in the provision of primary care services, although GPs were the least enthusiastic and saw CAM's role as limited. CAM practitioners were generally pro-integration.

Unsurprisingly, CAM practitioners were very positive about CAM, citing evidence for its effectiveness, and believed it to be commonly used and demanded by patients. The commissioners were generally positive about CAM, although this may reflect potential selection bias towards pro-CAM commissioners.

"I am very pro a more holistic approach" (commissioner 2)
GPs and CAM practitioners both saw MSK-MH comorbidity commonly in their practice. For GPs, common examples were fibromyalgia, "frequent attenders"/"heart sink patients", overweight, back/chronic pain with anxiety/MH issues, and osteoarthritis. Many CAM practitioners gave examples of comorbidity and how CAM (in their opinion) could help treat it.

"I think most of the patients in general practice have more than one thing going on, so most patients with, you know, anxiety or depression have something else going on. Not all, but most, most I would say.

Particularly perhaps when they get into their sort of 30 s or 40 s or whatever" (GP B2)

"there's definitely an inter-connectedness, particularly with back pain and erm, mental health issues" (GP A9)

"I was just thinking I would love to see someone with just one problem. I was trying to think when was the last time? - I actually can't remember" (CAM C6)

GPs and CAM practitioners both identified challenges in treating comorbidity, mainly NHS service issues, for example waiting lists for physiotherapy or pain clinics. CAM practitioners felt conventional treatment was often of limited benefit. Commissioners also recognised these challenges (although comorbidity per se did not tend to influence their decisions).

"I just feel that the services that we have to use on these people, such as the pain clinic and MATS [Musculoskeletal Assessment Triage Service] are often not meeting their needs" (GP A10)

"[Patients say] "Oh, well the GP just dishes out painkillers", and it doesn't solve the roots of their issue, their problem. So they'll come to me. They say "I want a more holistic approach"”(CAM A2.2) 
There was some agreement across all three groups that CAM had a role in treating MSK-MH comorbidity, given the limited conventional treatment options or availability. Some GPs felt that something extra, possibly CAM, was needed to offer these patients. CAM practitioners explained that CAM can treat comorbidity using a holistic approach.

"those chronic pain patients who, we all know who they are in our practice, we all dread them popping up on our list, and we need something else to work with them, because more and more evidence says that actually up titrating opiates, has lots of implications, it isn't good for our prescribing, it has lots of side effects for them. So we need something else to reach for, instead of our prescription pads, for these group of patients [chronic pain]. And I think that's sort of the other side of it, that almost makes it a little bit exciting in the sense that it's [integrative medicine] a new area that we could maybe tap into and get some real benefits" (GP B1)

\section{Is integrated medicine feasible in NHS primary care?}

A number of GPs highlighted concerns that integrating CAM into NHS primary care would present challenges and might not be feasible. Although many of these concerns were only raised by a few GPs, the repeated emergence of the message across several themes justifies its inclusion as a key issue.

First, CAM was seen by a small number of GPs to be addressing much broader problems than those which primary care should be treating, described by two GPs as 'first world problems' - issues around wellbeing, preventative care, dis-ease. Similarly, some GPs saw CAM as a form of self-care overlapping with social support and exercise. This view of CAM contrasted with the GP's primary role in treating disease.

"the extended, sort of, integration of integrated medicine is that there will be all of these services potentially who we could then refer into. And you're creating the burden of dis-ease rather than disease, and then you're increasing our burden" (GP A6)

Second, a small number of GPs, contemplating integrated medicine becoming part of their practice, thought it would involve fundamental changes to the GP consultation and communication i.e. becoming more patientcentred and 'meaningful'. This was challenging, given the limitations and pressures of UK primary care (bureaucracy, overwork, time constraints).
"There's lots of competing priorities though in terms of GP time, so where do you put complementary medicine as a priority?" (GP B4)

\section{Barriers to integration - The brick wall between CAM and NHS care}

A central message, occurring across several themes (mostly from CAM practitioners), was the idea that CAM and conventional medicine have significant conceptual differences which are barriers to integration. The language used strengthens these data. CAM practitioners regarded CAM as holistic, promoting self-care and behavioural change, while conventional care was described as reductionist, paternalistic and passive. They perceived the conceptual differences between the "two worlds" of "mainstream medicine" and CAM as a barrier to integration.

"[CAM is] a completely different concept of really how the world is" (CAM A1.9)

"the Western approach is very much more reductionist, ooking for diagnosis. Whereas I think there's a completely different approach from complementary therapies which is looking at a holistic and outward perspective. So there's quite a lot of adjustments to be made which I think an NHS approach can't cater for" (CAM C9)

Many CAM practitioners were concerned that attempts to overcome these differences would 'secularise', reduce and standardise CAM, and reduce the techniques practitioners could use, diminishing its value and holistic nature and reducing benefits. A few GPs concurred with this view, demonstrated by their concerns about feasibility of true integration in primary care.

"If you secularised qigong totally, if you strip it from all its, in a sense its spiritual value...if you take away the underlying principles in a sense, if you take away the theory and the philosophy... you leave it with a shell...just a form of exercise, a callisthenic, a dynamic movement exercise, a meditation without meditation" (CAM A2.1)

"there seems to be a sort of slight debate going on as to whether you could really, sort of, provide the range of services an osteopath would do privately within the NHS setting... a bit like trying to put a square peg into a round hole and whether or not you lose what, you know, what we think osteopathy is good for, or the good points" (CAM A1.6) 
"I think the danger about being integrated into the Health Service if, if, if it stays as it is, is we'll just be very limited as to what we can do" (CAM C4)

CAM practitioners saw CAM being used in the NHS more out of desperation - when conventional care fails or cannot offer anything more - than for its ability to prevent ill-health and promote wellness. They thought true and worthwhile integrative medicine would require a major change to conventional medical thinking, a view which some GPs also expressed. The only constructive suggestion for overcoming the gap between the 'two worlds' was through the planned changes in the NHS 'Five Year Forward View (a policy document describing a new shared vision for the future of the NHS and new models of care which aimed to reduce health disparities and improve care).

For CAM practitioners, structural barriers such as NHS guidelines and bureaucracy were very challenging. Their emotional language emphasised the importance of this theme. Commissioners agreed that guidelines were very influential in their decisions. For GPs, key structural barriers were lack of time and competing priorities in GP consultations.

"...the therapists round here all have something to give, but at the moment we all just seem to be bashing our heads to a large extent against a large brick wall and hopefully this [project] is a chink in the wall" (CAM C8)

“[We] don't have time during a GP consultation to give advice on CAM, you tend to move on to things which are more relevant to you as a GP, which you feel more confident about and which you have more knowledge about or can do something about" (GP B2)

Evidence of effectiveness appeared more important to CAM practitioners than GPs or commissioners. For CAM practitioners, evidence was the most important facilitator of integration and generating and implementing evidence was the biggest barrier.

“...that's one of the things that's incredibly difficult to get anything in to the NHS, it relies on evidence base. And, you know, whether it's complementary or an orthodox approach, it's got to have evidence base"

(CAM C6)

For commissioners, the main factor influencing their commissioning decisions was evidence of cost-saving or affordability, and the current cold financial climate posed the biggest challenge to commissioning. Restrictive funding models were also seen as challenging, especially in general practice. CAM practitioners also recognised the importance of evidence of cost-saving which was the only way' to obtain NHS funding for CAM.

"...even drugs that come into us with really good evidence, um, we're having to say, "where can you find the money to pay for this new treatment"" (commissioner 3)

"...everything has to be either cost neutral or saving money. That's the kind of mantra, so it's quite a difficult climate to suggest new services" (commissioner 7)

\section{GP knowledge}

For GPs, a clear theme was the need to improve their knowledge and education about CAM, which commissioners and CAM practitioners agreed with. Lack of dialogue between the two professions was a related issue. The importance of GPs' lack of knowledge and understanding of CAM reflects concerns that integration would extend the role of the GP beyond their current abilities or comfort zone.

"I would say my big barrier is my current understanding. I think it comes back to at the end of the day of my actual knowledge of what's available and what's proven erm, and locally what's sort of available" (GP B1)

“...there's a lack of education, formal education about complementary medicine at all, in GP training. We often just pick it up as we go along" (GP B4)

"So I think if you can even get [medical] students before they're qualified to know what's out there [CAM], know what the evidence base is, know who is regulated, know the training and the hoops that people have to jump through, I think it will be really helpful. I think the CCGs yes, but it's too late, because you've got to get the GPs with that knowledge earlier" (CAM C6)

\section{Governance of CAM}

Regulation of CAM practitioners was not a major issue for participants although some CAM practitioners felt that greater regulation of practitioners, and improved NHS awareness of regulation, were important. GPs did not mention regulation as a major factor, but that may be due to lack of awareness of the issues. 
"I don't see the chance of [hypnotherapy] getting integrated into NHS and NHS funded practice as long as there is a lack of regulation" (CAM A2.3)

"it's giving confidence to the, to the GPs if they are referring to a CAM then if you are $\mathrm{CNHC}$ [Complementary and Natural Healthcare Council] registered, then there is a lot of, um, ground to that" (CAM C5)

Commissioners' views varied on whether regulation of CAM practitioners would influence their decisions.

"...if it's mainstream, those are fairly standard, for example, you know, a doctor or a nurse or a therapist for example, but when it comes to some of the alternative or complementary therapies then I don't think always the systems are necessarily quite as rigorous" (commissioner 5)

"[Regulation] is something really that I do not want...imposed on all these other people [CAM practitioners]...The regulation in the health service is an unmitigated disaster now and is costing the system a fortune with...no evidence that it improves quality" (commissioner 6)

\section{Models of integration}

CAM practitioners, GPs and commissioners all felt that CAM might address some limitations of NHS provision for patients with MSK-MH comorbidity. For example, where waiting times for NHS treatment were long or the course of treatment/consultations too short; where lifestyle change or an active approach could reduce secondary care burden; where additional treatment options were needed; or to create a more holistic service.

"People, at the moment, are frustrated because they're, they're going to doctors and they're being like, sometimes given just an option of pain relief or physio, but there's a waiting list which is too long for them" (CAM A2.2)

CAM practitioners varied in their views as to whether paying for CAM can improve commitment, adherence, and its perceived value, and that co-payment by patients, on a sliding scale depending on ability to pay, might be the best model. This was also seen as a way of raising awareness of the cost of healthcare, including NHS care, which is often not clear to patients.

"I would see that you would have perhaps council paying a third, NHS paying a third, and it would be wonderful if the patient paid a third to show a commitment. Would be a nice vision. Would help with the cost saving [laughs]." (CAM A1.2)

Commissioners suggested models for integrating CAM into NHS services. The most promising appeared to be integrated personal commissioning budgets (a scheme using personal health budgets for patients/carers to take more control over their health, and to integrate health, social care and voluntary services) and social prescribing, although the available data have limited generalisability and these models are wider than just CAM. Signposting to CAM (mentioning it without formally referring patients) was also mentioned. Alternatives to NHS-funding were suggested, including charity-funding, voluntary practitioners and public-sector funding. Other considerations included improving communication between CAM and NHS practitioners (which was reported as poor by GPs), and providing CAM through a social enterprise.

\section{Discussion}

Summary of findings

GPs, CAM practitioners and commissioners agreed that CAM may be useful to address the limitations of NHS care for the prevalent issue of MSK-MH comorbidity, which include availability and limited effective treatments. Exercise- or self-care-based CAMs were the most acceptable to GPs.

Although they agreed that MSK-MH comorbidity is prevalent and burdensome and needs a new approach, the three groups' views on the barriers to using CAM within the NHS varied. A central message regarding integration was the different understandings of health between CAM and conventional medicine, which were likely to impede integration. CAM practitioners and GPs were concerned about integration fundamentally changing the care they provide, and both groups agreed that GPs' lack of education, knowledge, and understanding regarding CAM was a barrier to integration. For CAM practitioners, NHS structural barriers were a major hurdle. For GPs, lack of time and resources and current pressures were important issues, causing them to feel integration of CAM was beyond their capability. GPs emphasised that integrated medicine would have to relieve their burden rather than add to it. In terms of facilitating integration, evidence was more important to CAM practitioners than GPs and certainly than commissioners, who were more focussed on cost saving. Governance was not a major issue.

Various models of integration were discussed, with little consensus. GPs and commissioners saw an overlap of CAM with social support and exercise and current UK policy regarding self-care and patient activation. 
Integration could therefore be seen as one facet of social prescribing and holistic GP care.

\section{Comparison with previous literature}

A systematic review has confirmed that GPs see comorbidity as challenging to treat [51]. Our results support previous findings that GPs see MSK pain as an effectiveness gap suitable for an integrated/integrative approach $[12,13,29,30]$, and suggest this also applies to MSK-MH comorbidity. GPs' preference for exercise- or self-care- based CAM aligns with UK healthcare guidelines for low back pain (NICE guideline NG59), depression (NICE guideline CG91) and anxiety (NICE guideline CG113).

Our findings confirm previously identified challenges of integration that are recognised by UK healthcare professionals and may apply to MSK-MH comorbidity. These include: different 'world-views' in understanding health/health care $[16,37,52]$; concerns about secularising CAM when integrating $[12,19,20]$ or having to fundamentally change conventional care [16]; NHS bureaucracy (for CAM practitioners) [31, 53]; GPs' lack of knowledge and need for education in CAM [54-56]; and lack of time in NHS settings [31, 39]. GPs' concern that integration of CAM was beyond their current capacity appears to be a new finding and is discussed under Implications below. Although we focussed on an integrated (selective incorporation) model in our topic guides, the challenges raised by participants, particularly those regarding the conceptual differences between CAM and biomedicine, are more pertinent to a transformative model of integration -described by GP A6 as "the extended...integration of integrated medicine". They confirm the view that transformative integration may be a 'utopian ideal' [19].

The concern about 'trying to put a square peg into a round hole' - the 'secularisation' of CAM - is raised by Hollenberg \& Muzzin, as 'colonisation' of CAM [57]. Wiese and colleagues found that incompatibility between the ethos of science and CAM mean integration often involves 'co-optation' of CAM, and biomedical domination. There are examples of such secularisation in mindfulness-based approaches and herbal medicine [58, 59].

Poor GP knowledge implies education is needed about CAM - in the UK GPs are keen [29] and in the USA, CAM is often part of the medical curriculum [60]. Inter-professional education is an option [61].

The relatively low importance commissioners gave to evidence is interesting, but confirms findings from conventional medicine [62]. That CAM practitioners believe evidence is important has been reported before [63, 64]. However, CAM practitioners may lack research training [65], and have concerns about the appropriateness of traditional research methodology in CAM [66, 67].
Commissioners' emphasis on cost-saving evidence reflects an emphasis on prioritisation of health service funding [68] and more economic evidence is needed for CAM [69].

\section{Implications}

In our study, all three groups of healthcare professionals believed that an integrated approach using certain CAM may be worth pursuing to address limitations of conventional approaches in treating MSK-MH comorbidity, but they had different concerns about how an integrated approach might be implemented.

Findings highlight the burden that GPs are carrying in the UK - their workload has substantially increased $[70,71]$, a significant proportion of which is MSK and $\mathrm{MH}$ conditions [72, 73]. This 'crisis' creates reluctance to even contemplate anything new, e.g. integrated medicine, even if potentially beneficial. GPs and commissioners both felt successful integrated medicine would need to relieve NHS pressures, by reducing GP burden and costs. Integrating CAM may relieve GP workload for patients with limited treatment options [37]. Our study confirms 2003 findings that GPs and commissioners see integration of CAM as potentially helping to meet NHS targets [68]. Current policy drivers include the self-care and patient activation components of the NHS England Five Year Forward View [25, 28], in which primary care is central [26]. This aligns with "expansionism"- which favours the inclusion of alternative approaches [26, 74] e.g. social prescribing and holistic care. Conversely, some GPs' concerns about integration reflect "reductionists" arguments for GPs to reduce their duties to focus on the "genuinely vulnerable and sick" [75]. This is in line with the 2004 General Practitioner contract which has resulted in GPs practicing a more biomedical model of health and illness [76].

In terms of an integration model, transformative models are unlikely to be successful due to severe restrictions on NHS spending and concerns that these models would necessitate secularisation of CAM or fundamentally changing conventional care [77]. Instead, selective incorporation using referral from NHS primary care, as in social prescribing, may help the NHS address the needs of comorbid patients. Social prescribing is increasingly popular, with a national social prescribing network [78], and funding for social prescribing schemes/interventions from the UK Department of Health [79]. Regulatory implications GPs would need to be sure of CAM practitioners' regulation, quality and safety - may necessitate CAM practitioners becoming allied health practitioners, facilitated by the Professional Standards Authority's CAM registers [80]. This referral model would require GP education and referral protocols/guidelines [20,56], and has cost implications, as CAM is almost always patient-funded or part-funded [81, 82]. Co-payment by patients/NHS may 
be an option, but has equity implications and would need to consider ability to pay, particularly as MSK-MH comorbid patients tend to be of lower socioeconomic status [83, 84]. The King's Fund recently rejected the controversial issue of patients paying for NHS treatment [85]. Another funding option is public health funding, given the overlap between integrative medicine, preventative medicine and public health [86].

For anyone attempting to integrate CAM into a conventional health system we suggest: identifying the evidence for effectiveness and cost-effectiveness; careful consideration of terminology; working with practitioners to develop a CAM approach which respects the philosophies of both conventional medicine and CAM; considering exercise- or self-care-based CAM; including education for GPs; and linking to relevant conventional health policies/strategic priorities e.g. in the UK the Five Year Forward View [56].

There is a need for more evidence of effectiveness and particularly cost-effectiveness of CAM; MSK-MH comorbidity is a fertile area for research. Exercise- and self-care-based CAM may be the best approaches to evaluate as they appear to be most acceptable to GPs.

\section{Strengths and limitations}

We were successful in recruiting a large number of practitioners, however we did not aim for data saturation so a larger sample may provide new themes or understandings. Purposive sampling captured the views of a wide range of individuals, and we met all the criteria in our sampling frame, despite GPs' limited availability. However, the professionals who took part were likely to have a more pro-CAM stance than average, which may mean our results are skewed towards the positive aspects of an integrated approach. The researcher's pro-CAM stance may have biased responses although we made efforts to emphasise that we were interested in a range of views and remaining grounded in the objective data from the literature review phase. Commissioners were very difficult to recruit, due to lack of a central organising body or mailing list, and busy schedules. For the large part, we relied on personal contacts, giving a skewed sample with mainly positive experiences regarding commissioning CAM. Their limited availability to attend a focus group necessitated more one-on-one interviews, which may have influenced the findings. More research with commissioners would be very valuable.

\section{Conclusions}

GPs, commissioners, and CAM practitioners felt that integration of CAM may offer a useful solution to the challenges faced by the NHS in treating MSK-MH comorbid patients. However, integration of CAM into NHS care/settings for these patients is limited by structural barriers, philosophical differences and concerns about changing both types of care fundamentally. Selective incorporation using referral from NHS primary care into CAM services may be a feasible model of integration, although cost implications would need to be addressed, possibly through models such as social prescribing or co-payment. Regulatory issues would also need to be addressed, including raising GPs' awareness of CAM registers.

\section{Additional file}

Additional file 1: Focus group/interview topic guides. (DOCX 28 kb)

\section{Abbreviations}

CAM: Complementary and alternative medicine; CCG: Clinical commissioning group; MH: Mental health; MSK: Musculoskeletal; NHS: National Health Service; RCT: Randomised controlled trial

\section{Acknowledgements}

We are very grateful to the participants in the study. We would also like to thank Mwenza Blell and Kate Morton for their assistance in running the focus groups.

\section{Funding}

The report is based on independent research commissioned and funded by the NIHR Policy Research Programme (The Effectiveness And Cost Effectiveness Of Complementary And Alternative Medicine (CAM) For Multimorbid Patients With Mental Health And Musculoskeletal Problems In Primary Care In The UK: A Scoping Study). The views expressed in the publication are those of the author(s) and not necessarily those of the NHS, the NIHR, the Department of Health, 'arms' length bodies or other government departments.

\section{Availability of data and materials}

Original transcripts and analysis frameworks are available on request from $\mathrm{AL}$ : ava.lorenc@bristol.ac.uk.

\section{Authors' contributions}

$\mathrm{DS}, \mathrm{GF}, \mathrm{PL}, \mathrm{SH}, \mathrm{SM}, \mathrm{AL}$ and $\mathrm{HM}$ collaboratively developed the topic guides and helped provide sources of participants. AL organised recruitment for, conducted and analysed the focus groups, and drafted the paper. HM assisted in running one set of focus groups. DS, GF, PL, SH, SM, AL and HM revised the draft paper and read and approved the final version.

\section{Ethics approval and consent to participate}

The study was approved by the University of Bristol Faculty of Medicine and Dentistry Research Ethics Committee (FREC) on 3rd July 2015, reference 21,603 . All participants in the focus groups were provided with an information sheet, gave written informed consent and were free to withdraw from the study at any point.

\section{Consent for publication}

Not applicable

\section{Competing interests}

The authors declare that they have no competing interests.

\section{Publisher's Note}

Springer Nature remains neutral with regard to jurisdictional claims in published maps and institutional affiliations.

\section{Author details}

${ }^{1}$ Centre for Academic Primary Care, School of Social and Community Medicine, University of Bristol, Canynge Hall, 39 Whatley Road, Bristol BS8 2PS, UK. ${ }^{2}$ Primary Medical Care, Faculty of Medicine, University of Southampton, Aldermoor Close, Southampton SO16 5ST, UK. ${ }^{3}$ General Practice and Primary Care, Institute for Health and Wellbeing, University of Glasgow, 1 Horseletthill Road, Glasgow G12 9LX, UK. ${ }^{4}$ Department of Health Sciences, University of York, Heslington, York YO10 5DD, UK. 
Received: 24 April 2018 Accepted: 9 October 2018

Published online: 29 October 2018

\section{References}

1. Hartvigsen J, Hancock MJ, Kongsted A, Louw Q, Ferreira ML, Genevay S, Hoy D, Karppinen J, Pransky G, Sieper J, et al. What low back pain is and why we need to pay attention. Lancet. https://doi.org/10.1016/S0140-6736(18)30480-X [e-pub ahead of print].

2. Department of Health: The Musculoskeletal Services Framework: A joint responsibility: doing it differently. In.; 2006

3. Office for National Statistics (ONS): Sickness Absence Report. In.; 2016.

4. Davies SC. Annual Report of the Chief Medical Officer 2013, Public Mental Health Priorities: Investing in the Evidence. London: Department of Health; 2014.

5. Knapp M, Lemmi V. The economic case for better mental health. In: Davies S, editor. Annual Report of the Chief Medical Officer 2013, Public Mental Health Priorities: Investing in the Evidence. London: Department of Health; 2014. p. 147-56

6. Gureje O, Von Korff M, Simon GE, Gater R. Persistent pain and well-being: a World Health Organization study in primary care. Jama. 1998;280(2):147-51.

7. Lepine JP, Briley M. The epidemiology of pain in depression. Hum Psychopharmacol. 2004;19(Suppl 1):S3-7.

8. Department for Work and Pensions, Department of Health: Work, health and disability green paper data pack, supplementary tables; source: table 1n. labour force survey april to june 2016. In.; 2016.

9. Gore M, Sadosky A, Stacey BR, Tai K-S, Leslie D. The burden of chronic low Back pain: clinical comorbidities, treatment patterns, and health care costs in usual care settings. Spine. 2012;37(11):E668-77.

10. NICE: Multimorbidity: clinical assessment and management NICE guideline [NG56]. In.; 2016

11. Mangin D, Heath I, Jamoulle M. Beyond diagnosis: rising to the multimorbidity challenge. BMJ. 2012;344:e3526.

12. Wye L, Shaw A, Sharp D. Designing a 'NHS friendly' complementary therapy service: a qualitative case study. BMC Health Serv Res. 2008;8(1):173.

13. Fisher P, van Haselen R, Hardy K, Berkovitz S, McCarney R. Effectiveness gaps: a new concept for evaluating health service and research needs applied to complementary and alternative medicine. J Altern Complement Med. 2004; 10(4):627-32.

14. Alwhaibi M, Bhattacharya R, Sambamoorthi U. Type of multimorbidity and complementary and alternative medicine use among adults. Evid Based Complement Alternat Med. 2015;2015. https://doi.org/10.1155/2015/362582.

15. Bystritsky A, Hovav S, Sherbourne C, Stein MB, Rose RD, Campbell-Sills L, Golinelli D, Sullivan G, Craske MG, Roy-Byrne PP. Use of complementary and alternative medicine in a large sample of anxiety patients. Psychosomatics. 2012;53(3):266-72

16. Wiese M, Oster C, Pincombe J. Understanding the emerging relationship between complementary medicine and mainstream health care: a review of the literature. Health (London). 2010;14(3):326-42.

17. Luff DT, Kate. Models of complementary therapy provision in primary care In: Medical care research unit. Sheffield: Medical Care Research Unit, University of Sheffield; 1999.

18. Hu X-Y, Lorenc A, Kemper K, Liu J-P, Adams J, Robinson N. Defining integrative medicine in narrative and systematic reviews: a suggested checklist for reporting. Eur J Integr Med. 2015;7(1):76-84

19. Hollenberg D. Uncharted ground: patterns of professional interaction among complementary/alternative and biomedical practitioners in integrative health care settings. Soc Sci Med. 2006;62(3):731-44.

20. Chung VCH, Ma PHX, Hong LC, Griffiths SM. Organizational determinants of Interprofessional collaboration in integrative health care: systematic review of qualitative studies. PLoS One. 2012;7(11):e50022.

21. Wilkinson J, Peters D, Donaldson J: Clinical governance for complementary and alternative medicine in primary care. Final Report to the Department of Health and the King's Fund 2004.

22. Thomas K, Coleman P, Nicholl J. Trends in access to complementary or alternative medicines via primary care in England: 1995-2001 results from a follow-up national survey. Fam Pract. 2003;20(5):575-7.

23. Templeman $\mathrm{K}$, Robinson A. Integrative medicine models in contemporary primary health care. Complement Ther Med. 2011;19(2):84-92.

24. Kemper KJ. APA Presendential address: holistic pediatrics $=$ good medicine Pediatrics. 2000;105:214-8.

25. Liberating the NHS white paper [https://www.gov.uk/government/publica tions/liberating-the-nhs-white-paper]. Accessed 15 Oct 2018.
26. Five Year Forward View [https://www.england.nhs.uk/ourwork/futurenhs/ nhs-five-year-forward-view-web-version/]. Accessed 15 Oct 2018.

27. Delivering the forward view: NHS planning guidance 2016/17-2020/21 [https://www.england.nhs.uk/ourwork/futurenhs/deliver-forward-view/]. Accessed 15 Oct 2018

28. At the heart of health: realising the value of people and communities [https://media.nesta.org.uk/documents/at_the_heart_of_health_-_realising_ the_value_of_people_and_communities.pdf]. Accessed 15 Oct 2018.

29. van Haselen RA, Reiber U, Nickel I, Jakob A, Fisher PAG. Providing complementary and alternative medicine in primary care: the primary care workers' perspective. Complement Ther Med. 2004;12(1):6-16.

30. Jarvis A, Perry R, Smith D, Terry R, Peters S. General practitioners' beliefs about the clinical utility of complementary and alternative medicine. Prim Health Care Res Dev. 2015;16(03):246-53.

31. Bishop FL, Amos N, Yu H, Lewith GT. Health-care sector and complementary medicine: practitioners' experiences of delivering acupuncture in the public and private sectors. Prim Health Care Res Dev. 2012;13(03):269-78.

32. Maha N, Shaw A. Academic doctors' views of complementary and alternative medicine (CAM) and its role within the NHS: an exploratory qualitative study. BMC Complement Altern Med. 2007;7(1):17.

33. Lipman L, Dale J, MacPherson H. Attitudes of GPs towards the provision of acupuncture on the NHS. Complement Ther Med. 2003;11(2):110-4.

34. Lorenc A, Blair M, Robinson N. Personal and professional influences on practitioners' attitudes to traditional and complementary approaches to health in the UK. J Tradit Chin Med Sci. 2014:1(2):148-55.

35. Brien S, Howells E, Leydon GM, Lewith G. Why GPs refer patients to complementary medicine via the NHS: a qualitative exploration. Prim Health Care Res Dev. 2008;9:205-15.

36. Perard M, Mittring N, Schweiger D, Kummer C, Witt CM. Merging conventional and complementary medicine in a clinic department - a theoretical model and practical recommendations. BMC Complement Altern Med. 2015;15(1):172.

37. Luff $\mathrm{D}$, Thomas KJ. Sustaining complementary therapy provision in primary care: lessons from existing services. Complement Ther Med. 2000:8(3):173-9.

38. Peters D, Chaitow L, Harris G, Morrison S. Integrating complementary therapies in primary care. London: Churchill Livingstone; 2002.

39. Paterson C, Britten N. The patient's experience of holistic care: insights from acupuncture research. Chronic IIIn. 2008;4(4):264-77.

40. Good medical practice [http://www.gmc-uk.org/guidance/index.asp]. Accessed 15 Oct 2018

41. Tong A, Sainsbury P, Craig J. Consolidated criteria for reporting qualitative research (COREQ): a 32-item checklist for interviews and focus groups. Int J Qual Health Care. 2007:19(6):349-57.

42. Ritchie J, Spencer L, O'Connor W. Carrying out qualitative analysis. In: Ritchie J, Lewis J, editors. Qualitative research practice: a guide for social science students and researchers. Edn. London: Sage Publications Ltd: 2003. p. 219-62.

43. Ritchie J, Spencer L. Qualitative data analysis for applied policy research. In: Bryman A, Burgess R, editors. Analysing qualitative data. London: Routledge; 1993.

44. Pope C, Ziebland S, Mays N. Qualitative research in health care: analysing qualitative data. BMJ. 2000:320:114-6.

45. Spencer L, Ritchie J, O'Connor W. Analysis:practices, principles and processes. In: Ritchie J, Lewis J, editors. Qualitative Research Practice. London: Sage Publications Ltd; 2003. p. 200-18.

46. Pope C, Ziebland S, Mays N. Analysing qualitative data. In: Pope C, Mays N, editors. Qualitative Research in Health Care. Volume 3rd Edition. Oxford: BMJ Books; 2006. p. 63-82

47. Denzin N, Lincoln YS. Collecting and interpreting qualitative materials. London: Sage Publications Ltd; 1998.

48. Rabiee F. Focus-group interview and data analysis. ProcNutrSoc. 2004;63(4): 655-60.

49. Arksey $\mathrm{H}$, Knight $\mathrm{P}$. Interviewing for social scientists: an introductory resource with examples. London: Sage Publications Ltd; 1999.

50. Seale C. The quality of qualitative research. London: Sage Publications Ltd; 1999.

51. Sinnott C, Mc Hugh S, Browne J, Bradley C. GPs' perspectives on the management of patients with multimorbidity: systematic review and synthesis of qualitative research. BMJ Open. 2013;3(9):e003610.

52. Quah SR. Traditional healing systems and the ethos of science. Soc Sci Med. 2003;57(10):1997-2012 
53. Cant $\mathrm{S}$, Watts $\mathrm{P}$, Ruston $\mathrm{A}$. The rise and fall of complementary medicine in National Health Service hospitals in England. Complement Ther Clin Pract. 2012;18(3):135-9.

54. Sewitch MJ, Cepoiu M, Rigillo N, Sproule D. A literature review of health care professional attitudes toward complementary and alternative medicine. Complement Health Pract Rev. 2008;13(3):139-54.

55. Niemtzow RC, Burns SM, Piazza TR, Pock AR, Walter J, Petri R, Hofmann L, Wilson C, Drake D, Calabria K, et al. Integrative medicine in the Department of Defense and the Department of Veterans Affairs: cautious steps forward. J Altern Complement Med. 2016;22(3):171-3.

56. Crane R, Kuyken W. The implementation of mindfulness-based cognitive therapy: learning from the UK health service experience. Mindfulness. 2013; 4(3):246-54.

57. Hollenberg D, Muzzin L. Epistemological challenges to integrative medicine: an anti-colonial perspective on the combination of complementary/alternative medicine with biomedicine. Health Sociol Rev. 2010;19(1):34-56.

58. Secular mindfulness: potential \& pitfalls [https://www.bcbsdharma.org/article/ secular-mindfulness-potential-pitfalls/]. Accessed 15 Oct 2018.

59. Singer J, Fisher K. The impact of co-option on herbalism: a bifurcation in epistemology and practice. Health Sociol Rev. 2007;16(1):18-26.

60. Kreitzer MJ, Mann D, Lumpkin M. CAM competencies for the health professions. Complement Health Pract Rev. 2008;13(1):63-72.

61. Willison KD. Advancing integrative medicine through interprofessional education. Health Sociol Rev. 2008;17(4):342-52.

62. Wye L, Brangan E, Cameron A, Gabbay J, Klein JH, Pope C. Evidence based policy making and the 'art' of commissioning - how English healthcare commissioners access and use information and academic research in 'real life' decision-making: an empirical qualitative study. BMC Health Serv Res. 2015:15:430.

63. Hall G. Attitudes of chiropractors to evidence-based practice and how this compares to other healthcare professionals: a qualitative study. Clin Chiropr. 2011;14(3):106-11.

64. Kim Y, Cho S-H. A survey of complementary and alternative medicine practitioner's perceptions of evidence-based medicine. Eur J Integr Med. 2014;6(2):211-9.

65. Hadley J, Hassan I, Khan KS. Knowledge and beliefs concerning evidencebased practice amongst complementary and alternative medicine health care practitioners and allied health care professionals: a questionnaire survey. BMC Complement Altern Med. 2008;8(1):45.

66. Hansen K. Attitudes to evidence in acupuncture: an interview study. Med Health Care Philos. 2012;15(3):279-85.

67. Barry CA. The role of evidence in alternative medicine: contrasting biomedical and anthropological approaches. Soc Sci Med. 2006;62(11): 2646-57.

68. Thomas KJ, Coleman P, Weatherley-Jones E, Luff D. Developing integrated CAM services in primary care Organisations. Complement Ther Med. 2003; 11(4):261-7.

69. Herman PM, Craig BM, Caspi O. Is complementary and alternative medicine (CAM) cost-effective? A systematic review. BMC Complement Altern Med. 2005;5:11.

70. Dale J, Potter R, Owen K, Parsons N, Realpe A, Leach J. Retaining the general practitioner workforce in England: what matters to GPs? A cross-sectional study. BMC Fam Pract. 2015;16(1):140

71. Neher JO, Borkan JM, Wilkinson MJ, Reis S, Hermoni D, Hobbs FD. Doctorpatient discussions of alternative medicine for back pain. Scand J Prim Health Care. 2001;19(4):237-40.

72. The Musculoskeletal Services Framework: A joint responsibility: doing it differently [http://webarchive.nationalarchives.gov.uk/20130107105354/http:/ www.dh.gov.uk/prod_consum_dh/groups/dh_digitalassets/@dh/@en/ documents/digitalasset/dh_4138412.pdf]. Accessed 15 Oct 2018.

73. No Health Without Mental Health: A cross-government mental health outcomes strategy for people of all ages [https:/www.gov.uk/government/uploads/system/ uploads/attachment_data/file/213761/dh_124058.pdf]. Accessed 15 Oct 2018.

74. Nearly two million patients to receive person-centred support to manage their own care [https://www.england.nhs.uk/2016/04/person-centred-support/]. Accessed 15 Oct 2018

75. GPs shun homeopathy as prescriptions halve [http://www.pulsetoday.co.uk gps-shun-homeopathy-as-prescriptions-halve/10984426.article\#.Vadlra3bKM8] Accessed 15 Oct 2018.
76. Checkland K, Harrison S, McDonald R, Grant S, Campbell S, Guthrie B. Biomedicine, holism and general medical practice: responses to the 2004 general practitioner contract. Sociol Health IIIn. 2008;30(5):788-803.

77. Wye L. Mainstreaming complementary therapies into primary care: the role of evidence, 'ideal' service design and delivery and alterations in clinical practice. Phd thesis: University of Bristol; 2007.

78. New National Social Prescribing Network Addresses NHS Healthcare Accessibility Issues [https://www.westminster.ac.uk/news-and-events/ news/2016/new-national-social-prescribing-network-addresses-nhshealthcare-accessibility-issues]. Accessed 15 Oct 2018.

79. Matthews-King A. Providers invited to bid for $£ 4 \mathrm{~m}$ worth of funding for social prescribing schemes. Pulse. 2017. http://www.pulsetoday.co.uk/ clinical/prescribing/providers-invited-to-bid-for-4m-worth-of-funding-forsocial-prescribing-schemes/20035430.article.

80. Let's Work Together [https://www.professionalstandards.org.uk/what-we-do/ accredited-registers/lets-work-together]. Accessed 15 Oct 2018.

81. Bodeker G, Kronenberg F, Public Health A. Agenda for traditional, complementary, and alternative medicine. Am J Public Health. 2002;92(10):1582-91.

82. Sharp D, Lorenc A, Morris R, Feder G, Little P, Hollinghurst S, Mercer SW, MacPherson $\mathrm{H}$. Complementary medicine use, views and experiences - a national survey in England. BJGP Open. 2018; Paper submitted for publication. https://doi.org/10.1016/S0140-6736(12)60240-2.

83. Barnett K, Mercer SW, Norbury M, Watt G, Wyke S, Guthrie B. Epidemiology of multimorbidity and implications for health care, research, and medical education: a cross-sectional study. Lancet. 2012;380(9836):37-43.

84. McLean G, Gunn J, Wyke S, Guthrie B, Watt GCM, Blane DN, Mercer SW. The influence of socioeconomic deprivation on multimorbidity at different ages: a cross-sectional study. Br J Gen Pract. 2014;64(624):e440-7.

85. Barker K: A new settlement for health and social care. In: The King's Fund; 2014.

86. Ali A, Katz DL. Disease prevention and health promotion: how integrative medicine fits. Am J Prev Med. 2015;49(5 Suppl 3):S230-40.

Ready to submit your research? Choose BMC and benefit from:

- fast, convenient online submission

- thorough peer review by experienced researchers in your field

- rapid publication on acceptance

- support for research data, including large and complex data types

- gold Open Access which fosters wider collaboration and increased citations

- maximum visibility for your research: over $100 \mathrm{M}$ website views per year

At $\mathrm{BMC}$, research is always in progress.

Learn more biomedcentral.com/submissions 